\title{
COMMENTARY
}

\section{First ripples in a tidal wave?}

\author{
Dr Hana Morrissey and Prof Patrick Ball
}

The importance of delirium as a component of cognitive impairment is well known to the readers of this journal, but little is known of the true incidence in the community. Accurate diagnosis of delirium used to require specialist input, but two years ago, in this journal, Richardson et al. (2017) demonstrated the reliability and specificity of a "combined arousal and attention testing procedure" for detecting delirium superimposed on dementia in hospital inpatients, where the patient is physically present. The paper by Luijendijk et al. (2019) in this journal takes this process two steps further with a questionnaire for caregivers. Two steps because, firstly, it has been validated for delivery over the telephone, and secondly, the input from usual caregivers provides a valuable additional perspective on what has changed about a patient.

The work of Richardson and Luijendijk is important, but also challenging to the whole sector. In their introduction, Luijendijk et al. document the very high estimates of the number of undetected delirium cases that may be in the community, noting that it may be missed in 40-60\% of hospitalized patients and nursing home residents (de Lange et al., 2013; Siddiqi et al., 2006). They note that for screening and detection, the sensitivity of the tool is more important than its specificity. Importantly, these new procedures are quick to administer and Luijendijk's questionnaire does not even require the patient to be present. They noted that this tool reduced the time from referral to the patient being seen by a specialist service from 31 to 11 days. The tools also have the potential to be taught to a wide range of practitioners who are involved in the care of the elderly and used in more settings than acute hospital admission or primary care teams. If this were to happen, more cases of delirium will be identified in a wide range of healthcare and social care settings, not all of which will have expertise in the management of frail cognitively impaired elderly patients.

So with these tools, delirium has a much higher chance of being effectively detected, but what happens then? Finding the condition does not identify the cause, but it does present a duty to refer or further investigate. To safely and effectively investigate and then manage all these newly identified cases will require guidelines and infrastructure that will require establishment, training, and resourcing.

Thanks to medical advances, people are living for longer, but often heavily based upon ongoing use of medication, and increasingly of multiple medications (World Health Organization, 2015). Delirium may be a consequence of a recent change in health such as the development of an infection. However, the gradual accumulation of a medication, or multiple medications, is more insidious. The majority of dosage forms are designed to treat a 70-kg man with normal renal and hepatic functions. Many reliable reference sources will describe drug-drug interactions (Preston, 2019), but with so many patients taking multiple medications, it is far less clear what happens when five or more drugs are taken together, most commonly at the same time, in an older patient with declining cardiac, renal, and hepatic function and over an extended period of time.

In clinical practice, on many occasions, when one health professional or a carer raises suspicion with medical staff that a patient's confusion may be due to a certain medication, a frequent response has been; "but it cannot be that, they have been taking it for years." Our personal clinical experience over many years demonstrates that it certainly can be. Medication accumulation is another hidden challenge (Alagiakrishnan and Wiens, 2004).

Biochemical changes are a common cause of delirium and may easily be precipitated by diuretics. For most heart failure patients, current management includes a diuretic, an angiotensin converting enzyme inhibitor (or angiotensin receptor blocker) with or without an aldosterone antagonist. Additionally, patients are frequently told to avoid consuming salt and regulate their fluids intake. As diuretics excrete sodium and the water goes with the sodium, plus the inhibition of aldosterone release and antagonism of its action, we find one easy explanation for the growing interest in hyponatremia as a frequently missed condition. This "depletional" form of hyponatremia occurs at serum sodium levels much closer to what is regarded as "normal," frequently identified with levels around 130-135 mmol/l, which is very different from the "dilutional" form seen with the syndrome of inappropriate antidiuretic hormone secretion produced by medications such as the selective serotonin reuptake inhibitors where levels of 118-125 mmol/1 are common (Saepudin et al., 2015; 2016).

In 2010, Fox et al. (2011) were able to link specific levels of anticholinergic medications to outcomes of morbidity and mortality. If we add in the reports of Boustani et al. (2008) and Lozano- Ortega et al. (2019), some may be surprised by the wide range of medications documented to have anticholinergic activity and a contribution to the total burden. Ball et al. (2013) in an Australian population of 4853 elderly patients found up to $33 \%$ with a total anticholinergic burden above Fox's $>4$ total anticholinergic burden limit.

In the absence of clear evidence as mentioned above, medication-induced delirium is often a default conclusion when no other reason has been found. Starting often with 10-15 concurrent medications to choose from as possible culprits is the first hurdle, and making changes in a frail population in a community setting is the second. The HOMER study (Holland et al., 2005) demonstrated that inadequately prepared pharmacists attempting to manage these complex cases can lead to negative outcomes, but Stewart et al. (1998) and Zermansky et al. (2002) found much better outcomes with a trained and prepared group. However, even when trained and prepared, Abed found it often difficult to have recommendations accepted 
and implemented (Abed et al., 2017). Working on medication changes in a community setting is necessarily slow and gradual, and this will need to be explained to patients, carers, and relatives. It is usually a process of making one change at a time and allowing time to assess the effects before making the next. This is the only reliable way in a community setting to avoid the "domino effect" of sudden multisystem deterioration (Heath and Phair, 2009).

Creating an infrastructure that can effectively utilize the information from these tools to bring about real change in outcomes will require time, a team effort, and a change of policy in health provider organizations. Detecting and treating this delirium will not be cheap; however, with an increasing elderly population, it is both better for patients and carers and cheaper for healthcare providers and taxpayers to enable more people to continue functioning independently in their own homes for as long as possible (World Health Organization, 2015).

One possible outcome from these new developments is that we make use of the tools in our own practice, continue to practice much as before, and the ripples fade into a smooth, calm surface as if they had never been. The alternative is that here is an opportunity and a challenge to make real change; by effective use of these tools and appropriate follow-up, millions of people worldwide can have their cognitive function and quality of life improved.

One of the most professionally rewarding things achieved in our own careers has been to, in collaboration with our colleagues, work with someone who was dependent for all cares at presentation and watch them recover into a functioning independent human being by adjustment of their medications.

It can be done. Will we let the ripples settle or will we ride the wave?

\section{Description of authors' roles}

Prof. Ball developed the initial outline for this manuscript, which was edited and expanded by Dr. Morrissey. Sections were assigned for each to develop before both edited the final version.

\section{PATRICK A. BALl AND HANA MORRISSEY}

School of Pharmacy, University of Wolverhampton, WV1 1LY, United Kingdom

Email: patrick.ball@wlv.ac.uk

\section{References}

Abed, H., Morrissey, H. and Ball, P. A. (2017). The effect of medication reviews on reducing medication anticholinergic burden in elderly patients. International Journal of Recent Advances in Multidisciplinary Research, 4, 3060-3065.

Alagiakrishnan, K. and Wiens, C. A. (2004). An approach to drug induced delirium in the elderly. Postgraduate Medical Journal, 80, 388-393. doi: 10.1136/pgmj.2003 .017236.

Ball, P. A., Morrissey, H. and Pilotto, L.S.J. (2013). Anticholinergic burden assessed using general practice electronic records. Journal of Pharmacy Practice and Research, 43, 202-205. doi: 10.1002/j.2055-2335.2013. tb00255.x.

Boustani, M., Campbell, N., Munger, S., Maidment, I. and Fox, C. (2008). Impact of anticholinergics on the aging brain: a review and practical application. Aging Health, 4, 311-320. doi: 10.2217/1745509X.4.3.311.

de Lange, E., Verhaak, P.F.M. and van der Meer, K. (2013). Prevalence, presentation and prognosis of delirium in older people in the population, at home and in long term care: a review. International Journal of Geriatric Psychiatry, 28, 127-134. doi: 10.1002/gps.3814.

Fox, C. et al. (2011). Anticholinergic medication use and cognitive impairment in the older population: the medical research council cognitive function and ageing study. Journal of the American Geriatrics Society, 59, 1477-1483. doi: 10.1111/j.1532-5415.2011.03491.x.

Heath, H. and Phair, L. (2009). The concept of frailty and its significance in the consequences of care or neglect for older people: an analysis. International Journal of Older People Nursing, 4, 120-131. doi: 10.1111/j.1748-3743.2009. 00165.x.

Holland, R. et al. (2005). Does home based medication review keep older people out of hospital? The HOMER randomised controlled trial. BMJ, 330, 293. doi: 10.1136/ bmj.38338.674583.AE.

Lozano-Ortega, G. et al. (2019). A review of published anticholinergic scales and measures and their applicability in database analyses. Archives of Gerontology and Geriatrics, doi: 10.1016/j.archger.2019.05.010.

Luijendijk, H. J., Quispel-Aggenach, D.W.P., Stroomer-van Wijk, A.J.M., Meijerink-Blom, A. H., van Walbeek, A. and Zuidema, S. U. (2019). A short delrium caregiver questionnaire for triage of elderly outpatients with cognitive impairment: a development and test accuracy study. International Psychogeriatrics, 33, 31-37. doi: $10.1017 /$ S1041610219001595.

Preston, C. (Ed.) (2019). Stockley's Drug Interactions. 12th edn. London: Pharmaceutical Press.

Richardson, S. J. et al. (2017). Detecting delirium superimposed on dementia: diagnostic accuracy of a simple combined arousal and attention testing procedure.

International Psychogeriatrics, 29, 1585-1593. doi: 10.1017/ S1041610217000916. 
Saepudin, S., Ball, P. A. and Morrissey, H. (2015). Hyponatremia during hospitalization and in-hospital mortality in patients hospitalized from heart failure. BMC Cardiovascular Disorders, 15, 88. doi: 10.1186/s12872-015- 0082-5.

Saepudin, S., Ball, P. A. and Morrissey, H. (2016). Patient and medication-related factors associated with hospitalacquired hyponatremia in patients hospitalized from heart failure. International Journal of Clinical Pharmacy, 38, 848-854. doi: 10.1007/s11096-016- 0296-3.

Siddiqi, N., House, A. O. and Holmes, J. D. (2006). Occurrence and outcome of delirium in medical in-patients: a systematic literature review. Age and Ageing, 35, 350-364. doi: 10.1093/ageing/afl005.

Stewart, S., Pearson, S., Luke, C. G. and Horowitz, J. D. (1998). Effects of home-based intervention on unplanned readmissions and out-of-hospital deaths. Journal of the American Geriatrics Society, 46, 174-180. doi: 10.1111/j .15325415.1998.tb02535.x.

World Health Organization (2015). World report on ageing and health. Geneva: World Health Organisation. Available at: https://www.who.int/ageing/publications/world-report- 2015/en/; accessed 28 November 2019.

Zermansky, A. G., Petty, D. R., Raynor, D. K., Lowe, C. J., Freemantle, N. and Vail, A. (2002). Clinical medication review by a pharmacist of patients on repeat prescriptions in general practice: a randomised controlled trial. Health Technology Assessment, 6, 1-86. doi: 10.3310/ hta6200. 